\title{
Incidence of Dural Injury during Craniotomy - a Single Center Study
}

\author{
Punam Limbu $^{1}$, Kaushila Dhimal ${ }^{1}$, Pushpa Biswakarma ${ }^{1}$ \\ ${ }^{1}$ Neurosurgery Operation Theatre, B and C Medical College Teaching Hospital and Research Center, \\ Birtamode, Jhapa, Nepal.
}

Correspondence:

RN Punam Limbu

Neurosurgery Operation Theatre, B \& C Medical College and Teaching Hospital \& Research

Center,Birtamode,Jhapa, Nepal.

Email: limbupunal4@gmail.com

Phone: +9779816311104

\begin{abstract}
Background: During a craniotomy, there is a high chance of unintentional dural tear and may occur in both layers or only in the outer layer.ith the objective to see the incidence of dural tear during craniotomy using high-speed craniotome, this study was performed. Materials and methods:This is a prospective analytical study collected over the duration of 4 months. Cases of craniotomy done using the craniotome were collected. Age was presented as mean and standard deviation (S.D). Gender, diagnosis, and dural tear were presented in frequencies and percentages. Analysis of gender, diagnosis categories, and age categories with a dural tear was done using the Fischer exact test. Similarly, Pearson's correlation was done between the number of burr holes made and dural tear in SPSS20. Results: There were a total of 25 craniotomies performed during the study period using craniotome. The mean age of presentation was 43.32 (17.65) years. The incidence of the dural tear was noted in $20 \%$ of the cases which includes a single layer or both the layers of the dura. There was a significant association between different age categories and dural tear; where elderly patients seem to have more percentage of the dural tear. Conclusion:There was a $20 \%$ incidence of dural tear during craniotomy with a significantly higher incidence in the elderly population.
\end{abstract}

Key words: Craniotomy, Dural Tear, Head Injury.

$\mathrm{C}$

raniotomy is the most common procedure done in neurosurgical patients. ${ }^{1-4}$ During a craniotomy, there is a high chance of unintentional dural tear which is attached to the skull bone., ${ }^{2,5,6}$ Dural tear may occur in both layers or only in the outer layer. With the objective to see the incidence of dural tear during craniotomy using high-speed craniotome, this study was performed.

\section{Methods and Materials:}

Type of study: Prospective analytical study

Sampling technique: Non-probability consecutive sampling

Sample size: 25 patients

Duration of study: 4 months

57

Date submitted: 03/05/2020

Date accepted: 29/05/2020
Site of study: B and C Medical College Teaching Hospital and Research Center, Birtamode, Jhapa, Nepal.

Inclusion criteria: All the cases of craniotomy performed during the study period.

Exclusion criteria: 1). Craniotomy performed without the use of craniotome like cases of posterior fossa lesion where only bone nibblers were used and cases where Gigli saw used for craniotomy.2). Cases where only one burr hole was made during surgery like chronic subdural hematoma drainage, external ventricular drainage, of ventriculoperitoneal shunt.3). Cases of depressed skull fracture causing a dural tear.

Data collection and analysis:All the consecutive patients who met the inclusion and exclusion criteria during the study period were collected. 
Name, age, gender, diagnosis, number of burrs, and dural tear were collected in preformed proforma. Age was presented as mean and standard deviation (S.D). Gender, diagnosis, and dural tear were presented in frequencies and percentages. Analysis of gender, diagnosis categories, and age categories with a dural tear was done using the Fischer exact test. Similarly, Pearson's correlation was done between the number of burr holes made and dural tear in SPSS20.

\section{Results:}

There were a total of 25 craniotomies performed during the study period using craniotome. The mean age of presentation was 43.32 (17.65) years. The majority being at 20-29 years of age group (Figure 1).

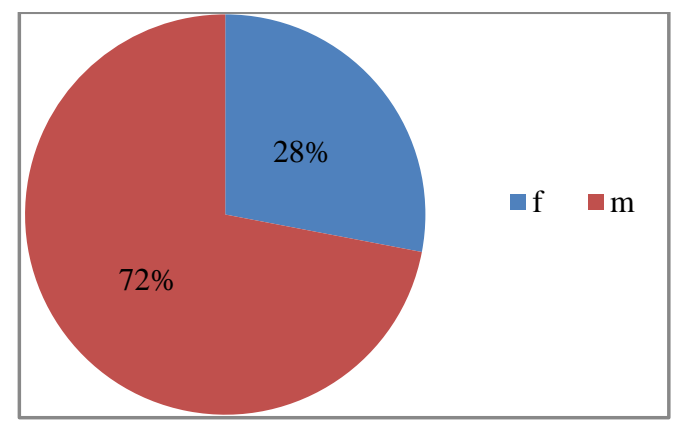

Figure 1: gender distribution

The majority of the patients who underwent craniotomy using craniotome were male (72\%)

(Figure 2).

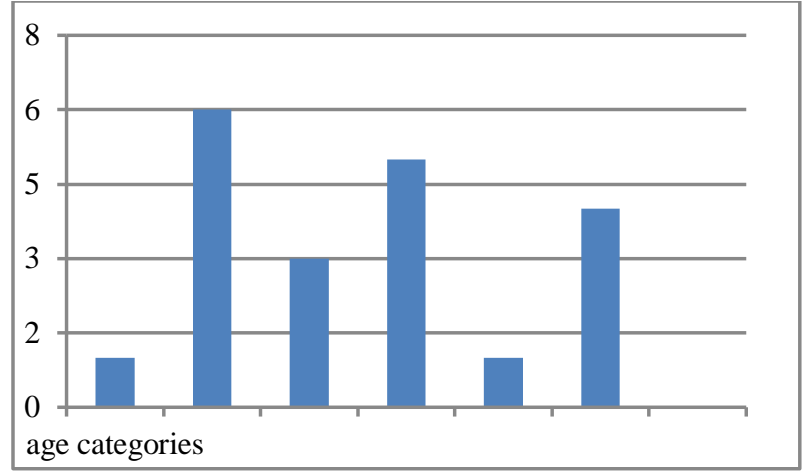

Figure 2: Distribution of age in different categories
The maximum number of craniotomies were done for a head injury during the study period, followed by intracerebral hemorrhage (ICH) (Figure 3).

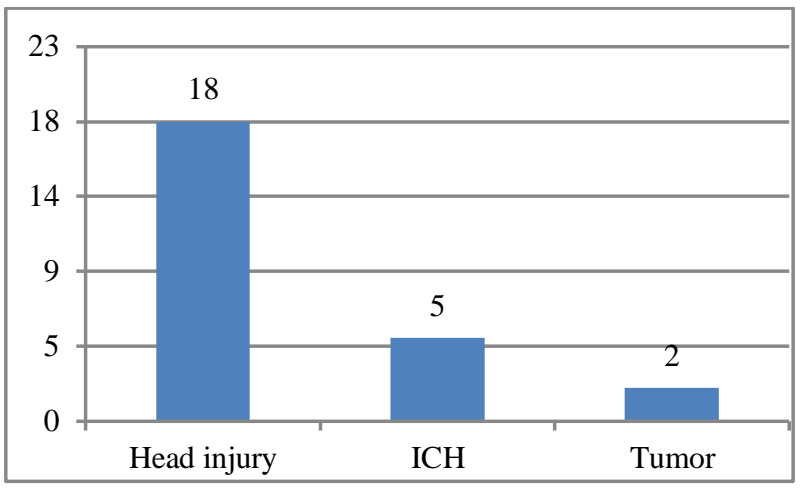

Figure 3: Various types of diagnosis

The incidence of the dural tear was noted in $20 \%$ of the cases which includes a single layer or both the layers of the dura (Table 1).

Table 1: Incidence of dural tear

\begin{tabular}{ccc}
\hline Dural Tear & Frequency & Percent \\
\hline Absent & 20 & 80.0 \\
Present & 5 & 20.0 \\
\hline
\end{tabular}

There was a significant association between different age categories and dural tear; where elderly patients seem to have more percentage of the dural tear (Table 2). However, gender and different categories of diagnosis were not significantly associated with the dural tear. Similarly, there was no significant correlation between the number of burr holes made and dural tear. 
Table 2: Association of gender and diagnosis with dural tear

\begin{tabular}{|c|c|c|c|c|c|}
\hline \multicolumn{2}{|c|}{ Variables } & \multicolumn{2}{|c|}{ Dural Tear } & \multirow[t]{2}{*}{ Total } & \multirow[b]{2}{*}{ P-value } \\
\hline & & 0 & 1 & & \\
\hline \multirow[t]{2}{*}{ Sex } & $\mathrm{F}$ & 4 & 3 & 7 & .113 \\
\hline & M & 16 & 2 & 18 & \\
\hline \multirow[t]{3}{*}{ Diagnosis } & Head injury & 14 & 4 & 18 & 1.000 \\
\hline & $\mathrm{ICH}$ & 4 & 1 & 5 & \\
\hline & Tumor & 2 & 0 & 2 & \\
\hline \multirow[t]{7}{*}{ Age categories } & $10--19$ & 1 & 1 & 2 & .023 \\
\hline & $20-29$ & 6 & 0 & 6 & \\
\hline & $30-39$ & 3 & 0 & 3 & \\
\hline & $40-49$ & 5 & 0 & 5 & \\
\hline & $50-59$ & 1 & 0 & 1 & \\
\hline & $60-69$ & 4 & 3 & 7 & \\
\hline & $70-79$ & 0 & 1 & 1 & \\
\hline
\end{tabular}

Table 3: Correlation between the number of burr holes made and dural tear

\begin{tabular}{cccc}
\hline & & Burrs & Dural Tear \\
\hline Burrs & Pearson Correlation & 1 & .085 \\
& Sig. (2-tailed) & & .686 \\
& $\mathrm{~N}$ & 25 & 25 \\
\hline \multirow{2}{*}{ Dural Tear } & Pearson Correlation & .085 & 1 \\
& Sig. (2-tailed) & .686 & \\
& $\mathrm{~N}$ & 25 & 25 \\
\hline
\end{tabular}

\section{Discussion:}

Dura is a tough structure protecting the underlying brain. Overlying the dura is the flat skull bone where dura gets adherent at the suture line. ${ }^{7}$ From the very beginning of the neurosurgery various technique of cutting bone without injury, the underlying dura has been developed. The initial instrument like Gigli saw which uses passer to protect the dura while cutting the bone were used in the early days. ${ }^{8,9}$ Overtime various high-speed drills had been developed which have a clubshaped base to protect the dura and a side cutting long cutters. ${ }^{10,11}$ Despite various development there is still evidence of dural tear during craniotomy. ${ }^{2,5}$ This might be due to advancing age, as in elderly 
the dura not only gets attached at the suture but is also stuck on the underlying flat surface of a calvarial bone. ${ }^{12}$ As seen in our study, age seems to a significant independent factor associated with the dural injury.

As seen in most of the neurosurgical unit throughout the world, head injury was the most common diagnosis in our study. ${ }^{1,3,13}$ Similarly, gender doesn't seem to be associated with an increased number of dural injury during craniotomy, which is similar to previous literature. ${ }^{2}$ Increasing the number of burrs to reduce the chance of dural injury is a common neurosurgical practice by many neurosurgeons; however, there was no any correlation between the numbers of burrs and dural tear in this study.

\section{Conclusion:}

There was a $20 \%$ incidence of dural tear during craniotomy with a significantly higher incidence in the elderly population.

\section{References:}

1. Thapa DK. Review of Neurosurgical services at B\&C Hospital in the last 3 years. Eastern Green Neurosurgery. 2019 Apr 30;1(1):2-6.

2. Engelhardt M, Uhlenbruch S, Christmann A, Miede C, Eufinger H, Scholz M, Harders A, Schmieder K. Accidential Dural Tears Occurring during Supratentorial Craniotomy-A Prospective Analysis of Predisposing Factors in 100 Patients. Zentralblatt für Neurochirurgie. 2005 May;66(02):70-4.

3. Ito M, Sonokawa T, Mishina H, Sato K. Penetrating injury of the brain by the burr of a high-speed air drill during craniotomy: case report. Journal of clinical neuroscience. 2001 May 1;8(3):261-3.

4. Nepal PR, Rijal S. Outcome Following Decompressive Surgery for Malignant Middle Cerebral Artery Infarction. Eastern Green Neurosurgery. 2020 Jan 29;2(1):23-6.

5. Biswakarma P, Limbu P. Dural Injury During Placement of Burrholes-Single Center Study. Eastern Green Neurosurgery. 2020 Jan 29;2(1):35-7.

6. Sahu RN, Das KK, Srivastava AK. Cranial Burr Hole. Manual of ICU Procedures. 2015 Aug 31:430.

7. Adeeb N, Mortazavi MM, Tubbs RS, Cohen-Gadol AA. The cranial dura mater: a review of its history, embryology, and anatomy. Child's Nervous System. 2012 Jun 1;28(6):827-37.

8. MC VAN DIJK RTWM THOMEER J. Use of the Gigli saw in performing a mid-frontobasal or pterional craniotomy. British journal of neurosurgery. 1997 Jan 1;11(6):558-9.
9. Shimizu S, Miyazaki T, Suzuki S, Yamada M, Utsuki S, Oka H, Fujii K. Supratentorial Craniotomy using a threadwire saw. Neurologia medico-chirurgica. 2008;48(4):191-4.

10. Pait GT, Dennis MW, Laws Jr ER, Rizzoli HV, Azzam CJ. The history of the neurosurgical engine. Neurosurgery. 1991 Jan 1;28(1):111-29.

11. Dujovny MI, Gundamraj R, Misra M. Instrumentation Report: High power drill systems in neurosurgery. Neurological research. 1997 Dec 1;19(6):654-6.

12. Murzin VE, Goriunov VN. Study of the strength of the adherence of the dura mater to the bones of the skull. Zhurnal voprosy neirokhirurgii imeni NN Burdenko. 1979(4):43-7.

13. Yadav AK, Rajbanshi JN, Kushwaha SK, Nepal PR. Prevalence of Head Injury of Patients Arriving in a Tertiary Care Center. Eastern Green Neurosurgery. 2020 Jan 29;2(1):38-41. 